\title{
Sobre a Negatividade do Conceito de Indivíduo em Adorno: a Resistência Possível ${ }^{1}$
}

\author{
Alexandre Lara de Moraes ${ }^{2}$ \\ Vara da Infância e Juventude e Varas de Família \\ Foro Regional de Pinheiros - São Paulo, SP
}

Este artigo analisa o conceito de indivíduo utilizado por Adorno na crítica social que marcou o Instituto de Pesquisa Social durante a década de 40. Para isso, foram estudados vários aforismos do livro Minima Moralia. A questão central é a relação possível entre a anulação da individualidade $e$ as possibilidades de resistência do indivíduo ressaltadas pelo autor. Nessa linha, são analisados conceitos como individualidade, mônada, isolamento, privilégio, humilhação, dever moral, solidariedade $e$ resistência.

Descritores: Adorno, Theodor Wiesengrund, 1903-1969.

Individualidade. Sociedade.

crítica social de Adorno sempre se destacou da crítica que, em geral, era
feita em sua época, e mesmo do que foi feito depois. Junto com Horkheimer, o autor escreveu algumas obras cujo grande diferencial, além do rigor e radicalidade crítica incomparáveis, está na maneira como lida na crítica social com a relação entre indivíduo e sociedade. Por meio dela, Adorno evidenciou de maneira cabal o caráter totalitário da sociedade na estandardização da cultura, na educação semiformativa, no esvaziamento dos fins humanos na

1 Este artigo é parte dos estudos que resultaram na Dissertação de Mestrado em Filosofia pelo Instituto de Filosofia e Ciências Humanas da UNICAMP, sob a orientação da Profa. Dra. Jeanne Marie Gagnebin, defendida em setembro de 2004.

2 Psicólogo graduado pelo Instituto de Psicologia - USP e Mestre em Filosofia pelo IFCH - UNICAMP. Psicólogo Judiciário da Vara da Infância e Juventude e das Varas de Família do Foro Regional de Pinheiros. Endereço para correspondência: R. Betel, 48 - ap. 12 - Mirandópolis, Sâo Paulo, SP. Endereço eletrônico: alexandre-lara@ uol.com.br 
ordem objetiva das instituições e na frieza e violência das relações, por assim dizer, "interpessoais". Ao mesmo tempo, mostrou o apequenamento e anulação dos indivíduos nos interstícios da sociedade do capitalismo tardio, que, pressionados objetivamente pela onipotência dos grandes grupos econômicos e subjetivamente pela indústria cultural e pela semiformação, acabam por ter sua individualidade negada e transformada em mercadoria, cujo valor segue a conveniência da racionalidade econômica vigente.

Todavia, é bastante marcante no autor a insistência de, ao mesmo tempo em que denuncia a anulação do indivíduo e critica toda e qualquer forma de enaltecer ou de eximir a falsa individuação, também repudia toda e qualquer tentativa de fazer do indivíduo o bode expiatório da barbárie vigente. Em outras palavras, apesar da situação de anulação pela socialização totalitária em que o indivíduo se vê enredado, Adorno insiste que o mesmo ainda resiste.

O presente artigo pretende discutir a seguinte questão: em face da situação de anulação do indivíduo pela socialização totalitária e tudo o que ela representa segundo os autores, como é possível ao indivíduo resistir? E, mais além, que tipo de resistência ainda é possível?

Para tanto, serão analisados alguns aforismos do livro Minima Moralia de Adorno. Essa obra, sob todos os ângulos, constitui-se como um esforço do autor em se debruçar sobre a esfera do particular, do privado e do individual para, a partir dela, entender de forma justa a injustiça contida no conceito de Universal. Longe de pretender fazer uma apologia do indivíduo como fonte da verdade e salvação do mundo, Adorno faz da experiência particular o ponto privilegiado para uma reflexão filosófica que se oponha ao que ele chamou de "primado do todo". A configuração aforismática do livro também reflete a escolha do autor pelo fragmento como forma de contraposição aos grandes sistemas filosóficos que, em sua pretensão de a tudo englobar, acabavam por “dissolver" o particular. Por fim, o próprio subtítulo da obra, Reflexões a partir da vida danificada, também mostra a opção do autor pelo evento cotidiano - principalmente no que diz respeito a tudo aquilo que o dia-a-dia guarda de particular, efêmero e, muitas vezes, insignificante - como meio de acesso revelador do todo social.

Ao final do aforismo 97, Adorno explicita a situação em que o indivíduo se encontra: 
Se hoje os últimos traços de humanidade parecem prender-se apenas ao indivíduo, como algo que encontra-se em seu ocaso, eles nos exortam a pôr um fim àquela fatalidade que individualiza os homens tão-somente para poder quebrá-los por completo em seu isolamento. (Adorno, 1993, p. 132)

É como sendo comparável a uma mônada que Adorno vê a forma de existência assumida pelo indivíduo à época de sua liquidação. Com isso, o autor pretende mostrar duas características básicas da individualidade na sociedade administrada e do capitalismo tardio: primeiro, sua condição de "célula" isolada do contato "ativo" (poderíamos dizer, consciente) com o meio social em que está envolvida, bem como com as demais "células" que compõem este meio. Esta, não obstante seu isolamento cego, traz em sua constituição a mediação social sob uma forma velada e, portanto, não reflexiva. Além disso, ao utilizar um conceito do século XVII que simboliza o átomo econômico individual da sociedade burguesa, como define Horkheimer em Eclipse of Reason, para conceituar um tipo social predominante, Adorno pretende mostrar até que ponto a existência do indivíduo e sua relação com a sociedade se devem "às formas da economia política, em particular ao mercado urbano" (Adorno, 1993, p. 130).

No aforismo "Mônada", Adorno visa à necessidade de desfazer a clássica oposição entre indivíduo e sociedade. Aqui, é necessário analisar melhor a idéia de o indivíduo não apenas ser originado pela sociedade, mas também estar envolto por ela. O que significa este "estar envolto"? Cito o autor:

Mesmo como oponente das pressões da socialização, ele [o indivíduo] permanece sendo seu produto mais característico e a ela semelhante. $\mathrm{O}$ que lhe permite a resistência, cada traço de independência, tem sua fonte no interesse individual monadológico e na cristalização deste como caráter. O indivíduo reflete precisamente em sua individuação, a lei social preestabelecida da exploração, por mais que esta seja mediatizada. (pp. 130-131)

O primordial nesse trecho diz respeito à necessidade de entender a relação do indivíduo com a dinâmica social que pretende sua liquidação. Segundo Adorno, o indivíduo deve ser visto como parte integrante de sua própria liquidação. Porém, essa afirmação não pode ser entendida com sendo o indivíduo, em última instância, o verdadeiro responsável por sua anulação. Pelo contrário, Adorno rejeita essa possibilidade imputando tal forma de tratamento da decadência do indivíduo a uma "crítica reacionária da cultura" (p. 130). 
Para ele, essa crítica seria viciada pelo mesmo erro que levou o indivíduo a seu atual estado, ou seja, aquele falso individualismo que, isolando o indivíduo, não promove sua emancipação, mas apenas faz dele o dócil e impotente representante último da deformação social:

Individualistas como Huxley e Jaspers amaldiçoam o indivíduo por causa de sua vacuidade mecânica e de sua fraqueza neurótica, mas o sentido dessa condenação é a idéia de que é preferível sacrificar o próprio indivíduo a criticar o principium individuationis social. Sua polêmica já é, enquanto meia-verdade, a inverdade inteira. A sociedade é descrita por eles como a convivência imediata de homens de cuja atitude o todo é conseqüência, e não como um sistema, que não só os encerra e deforma, mas penetra até aquela humanidade que um dia os determinava como indivíduos. Através dessa interpretação exclusivamente humana da situação como ela é, a crua realidade material, que conecta o ser humano à desumanidade, se vê aceita mesmo quando é denunciada.(p. 130)

Se, por este trecho, torna-se claro que não se trata, segundo a visão adorniana, de responsabilizar o indivíduo por sua desumanização, resta ainda entender o que Adorno quer dizer quando afirma que o indivíduo é parte integrante de sua anulação na sociedade. A primeira indicação para entendermos essa afirmação está no próprio trecho citado acima. Em certo momento, Adorno escreve: "mas o sentido dessa condenação é a idéia de que é preferível sacrificar o próprio indivíduo a criticar o principium individuationis social". É esse o ponto fundamental da análise adorniana da relação entre indivíduo e sociedade: segundo Adorno, os processos de individuação e socialização não podem ser separados, ambos estão imbricados desde o início. Portanto, dizer que o indivíduo deve a forma como exerce, ou não, sua individualidade à determinação social não é apenas dizer que o indivíduo é pressionado a ser de tal ou qual forma. Mais do que isso, é afirmar que ele já é constituído de maneira a não haver mais necessidade de uma pressão para que ele se comporte de uma forma específica. A própria idéia de pressão, nesse caso, trabalha com a existência de dois lados opostos e independentes: a sociedade e o indivíduo, este último teria suas disposições específicas e sofreria a pressão social para mudar "seu jeito de ser", o que, em Adorno, já está incorreto pelo simples fato de que o indivíduo não tem "um jeito de ser autêntico"3 independentemente do ambiente social.

3 Sobre o caráter falso do conceito de autenticidade em Adorno, cf. Moraes (2004). 
Há, entretanto, dois aforismos que ajudarão na compreensão mais aprofundada desta questão. No aforismo número 23, "Plurale tantum”, Adorno insiste no fato de que numa sociedade formada por indivíduos que se definem em função dos grupos a que pertencem, de forma a colarem-se em sua organização e, como que por simples decalque, adquirirem assim sua "personalidade", a possibilidade de entender mais profundamente esta sociedade está justamente no estudo do indivíduo e não no coletivo. Com isso Adorno tenta mostrar que o indivíduo tem sua organização subjetiva estruturada socialmente. Importante ressaltar que não se trata de uma estruturação formal. Mais do que isso, a individuação resulta numa subjetividade concretamente permeada pelos interesses e exigências da sociedade como um todo.

É na persecução dos interesses absolutamente particulares de cada indivíduo que se pode estudar com a maior exatidão possível a essência do coletivo na sociedade falsa, e pouco falta para que se tenha de conceber, desde o começo, a organização dos impulsos divergentes, sob o primado de um Eu ajustado ao princípio de realidade, como uma quadrilha de ladrões interiorizada, com chefe, sequazes, cerimonial, juramentos de fidelidade, traições, conflitos de interesse, intrigas e todos os demais ingredientes. (p. 38)

Eis do que trata o "principium indivituationis" mencionado por Adorno. A sujeição a que as formas sociais e econômicas, nas quais os indivíduos estão inseridos, submetem o processo de individuação não se dá por uma pressão externa, mas sim como infiltração na própria constituição da subjetividade. Esse mecanismo é mais extensamente analisado por Adorno no aforismo 147, "Novissimum organum". Neste aforismo, Adorno radicaliza ainda mais a afirmação que faz no início de "Mônada", quando diz que "o indivíduo deve sua cristalização às formas da economia política, em particular ao mercado urbano". Segundo Adorno, o fato de que a objetividade social penetra no mais íntimo da constituição subjetiva do indivíduo permite falar numa composição orgânica dos indivíduos como um prolongamento da composição técnica do capital:

A composição orgânica do ser humano não pára de crescer. Aquilo através de que os sujeitos são neles mesmo determinados como meios de produção e não como finalidades vivas cresce como a proporção das máquinas em relação ao capital variável. Os discursos habituais sobre a "mecanização" do homem são enganosos, porque o concebem como algo estático, que por "influências" de fora, através de uma adaptação a condições de produção a ele exteriores, sofre certas deformações. 
Mas não existe substrato algum dessas "deformações", nenhuma interioridade ôntica sobre a qual mecanismos sociais atuariam de fora apenas: a deformação não é nenhuma doença no homem, e sim uma doença da sociedade, que gera suas crias com aquela "tara hereditária", que o biologismo projeta na natureza. (p. 201)

Mediante o conceito de composição orgânica do homem, Adorno não se refere apenas àquelas habilidades especificamente criadas e adaptadas ao mundo do trabalho, mas principalmente àquelas instâncias que representariam justamente o oposto: os chamados impulsos naturais (mas que, na visão adorniana, já são fruto da dialética social). Com isso, Adorno quer denunciar aquilo para o que já apontava quando escreveu "Plurale tantum", ou seja: a própria organização psicológica pulsional do indivíduo reflete o processo social. Por toda as Minima Moralia há referências de Adorno ao Eu configurado como o diretor de empresa que deve "coordenar" e "gerenciar" as instâncias divergentes, "administrando" os conflitos com o objetivo de, com a "otimização" do funcionamento da empresa, melhorar a "publicidade" do "produto", promovendo, assim, sua melhor "valorização" no mercado.

Considerando a forma peculiar como Adorno concebe a relação entre individuação e socialização, pode-se perceber que a anulação do indivíduo não se dá de fora para dentro, mas como uma meta de realização individual engendrada socialmente. A idéia de uma anulação do indivíduo socialmente determinada como realização individual, por outro lado, indica que, com o termo anulação, Adorno não está querendo dizer que o indivíduo deixou de existir. Pelo contrário, com o conceito de anulação, Adorno pretende denunciar aquilo que de pior poderia ter acontecido com o indivíduo. Ou seja, a morte do indivíduo, consequiência radical da objetivação total da subjetividade, não significa a liquidação completa do mesmo (liquidação esta que ainda guardaria como possibilidade a esperança do surgimento de algo novo e que se opusesse à socialização totalitária), mas a permanência perversa de um modelo historicamente condenado.

É ainda muito otimista pensar que o indivíduo está sendo liquidado com osso e tudo. Pois mesmo na sua negação pura e simples, na supressão da mônada através da solidariedade, estaria plantada ao mesmo tempo a salvação do ser singular, que apenas na sua relação com o universal tornar-se-ia um particular. A situação atual está muito distante disso. A desgraça não ocorre como uma eliminação radical do que existiu, mas na medida em que o que está historicamente condenado é arras- 
tado como algo de morto, neutralizado, impotente, e se vê afundando de maneira ignominiosa. Em meio às unidades humanas padronizadas e administradas, o indivíduo vai perdurando. (...) Mas, na verdade, ele é ainda apenas a função de sua própria unicidade, uma peça de exposição como os fetos abortados que outrora provocavam o espanto e o riso nas crianças. (p. 118, aforismo 88)

A anulação do indivíduo, então, não diz respeito apenas ao cerceamento e impossibilidade do desenvolvimento da individualidade em todo o seu potencial humano, mas também diz respeito à manutenção de uma falsa idéia de individualidade que faz do isolamento cego a que submete as pessoas o meio de perpetuar os indivíduos, ainda que estes já estejam mortos. De acordo com Adorno, poderíamos dizer que o indivíduo está morto, mas para que continue existindo sem apresentar uma verdadeira resistência, a sociedade providencia seu empalhamento.

Torna-se claro, então, que tal anulação do indivíduo só se dá em virtude da forma monadária de sua existência. Ou seja, é só por meio do aumento do isolamento e do falso sentimento de auto-suficiência da mônada que a participação ativa dos indivíduos em sociedade pode ser reduzida até a sua nulidade completa. Tal qual já alertava Horkheimer em Eclipse of Reason: "Existe uma moral em tudo isso: Individualidade é prejudicada quando cada homem decide mudar por si mesmo"4 (Horkheimer, 1974). Com o isolamento da mônada, proporcionado pelo sentimento de "independência" e "auto-suficiência", a tensão (ou de acordo com Horkheimer, o equilíbrio de forças) entre indivíduo e sociedade tende, mediante a harmonização dos conflitos, a desaparecer e, com ela, a capacidade de resistência do indivíduo ao seu processo de anulação. Portanto, quando Adorno afirma, sem rodeios, que a liquidação do indivíduo seria algo realmente desejável, é a essa forma de existência, que traz consigo o embuste da falsa independência e pífia liberdade, que ele se refere.

Todavia, a análise realizada até agora não elucida a questão principal: como, diante desse contexto de anulação individual tão duramente criticado por Adorno, entender a perseverança do autor em insistir que a dominação não se dá por completo e que o indivíduo ainda resiste?

A presente análise do isolamento da mônada está incompleta porquan-

4 No original: "There is a moral in all this: individuality is impaired when each man decides to shift for himself". 
to abordou apenas seu aspecto de falsidade, relacionado à constituição da mônada que, apesar de seu isolamento, encarna dentro de si o mesmo princípio social ao qual se opõe. Entretanto, de acordo com Adorno, ao isolamento da mônada não estão ligados apenas o falso sentimento de auto-suficiência e o conceito enganoso de autenticidade, mas também outros sentimentos e conceitos que passamos a explorar agora. Para tanto, recomeçamos com o mesmo trecho do aforismo 97, citado acima:

Mesmo como oponente das pressões da socialização, ele [o indivíduo] permanece sendo seu produto mais característico e a ela semelhante. $O$ que the permite a resistência, cada traço de independência, tem sua fonte no interesse individual monadológico e na cristalização deste como caráter. O indivíduo reflete precisamente em sua individuação, a lei social preestabelecida da exploração, por mais que esta seja mediatizada. (Adorno, 1993, pp. 130-131, grifo nosso)

O trecho acima destacado indica haver uma forte relação entre o aspecto de isolamento da mônada individual e a capacidade de resistência do indivíduo. Importante também é o fato de que a possibilidade dessa ligação deriva do que parece ser uma qualidade implícita a tal isolamento: seu caráter de independência. Para tornar mais clara esta visão positiva do isolamento da mônada, passo a analisar alguns aforismos.

No aforismo 5, intitulado "Isso é bonito de sua parte, senhor doutor", Adorno adverte contra a falsa participação social:

É de bom alvitre desconfiar de tudo o que é ingênuo, descontraído, de todo descuidar-se que envolva condescendência em relação à prepotência do que existe (...) $\mathrm{A}$ conversa casual com o homem do trem, com quem manifestamos acordo através de um par de frases de modo a evitar discussão e das quais sabemos que, no fim das contas, chegam a ser um crime, já é até certo ponto traição; nenhum pensamento é imune à sua comunicação e já é suficiente dizê-lo no lugar errado e num consenso falso para minar sua verdade. De cada ida ao cinema, apesar de todo o cuidado e atenção saio mais estúpido e pior. A própria sociabilidade é participação na injustiça, na medida em que finge ser este mundo morto um mundo no qual ainda podemos conversar uns com os outros, e a palavra solta, sociável, contribui para perpetuar o silêncio, na medida em que as concessões feitas ao interlocutor o humilham de novo na pessoa que fala. (p. 19)

O texto procura mostrar que a pressão social sobre os indivíduos se tornou tão intensa que já não há mais espaço para o relaxamento, ainda que 
temporário, da tensão provocada por aquela pressão. O simples abandonar-se aos pequenos e inofensivos momentos de futilidade e indolência já implica, segundo Adorno, a participação na injustiça social. Isso porque não existe mais nada de inofensivo, de ingênuo ou inconseqüente. Até mesmo o simples contato ocasional com o outro, a troca de palavras desinteressada, já escondem o interesse geral de nunca ir além do contato superficial.

Dessa forma, os momentos de abandono e relaxamento não levam à fuga daquela pressão, ao contrário, apenas contribuem para que ela se intensifique, atingindo o indivíduo até os ossos. O próprio desejo de fuga da realidade opressiva, por meio da busca das "pequenas alegrias que parecem ser excluídas da responsabilidade do pensamento", por mais compreensível que possa parecer, segundo Adorno, é culpado da mais alta traição. Para o autor, trata-se de uma submissão que leva a um tipo de regressão que compartilha os mesmos princípios das tendências regressivas da vida pulsional. O aforismo 8, "Se os maus te atraem", deixa bem clara essa relação:

Existe um amor intellectualis em relação ao pessoal da cozinha, a tentação para quem se ocupa no plano teórico ou artístico, de acompanhar - tanto em termos de assunto, como da maneira de expressão - todos os possíveis hábitos que se rejeitaram quando a percepção estava alerta. (...) O que vale para a vida pulsional, vale igualmente para a espiritual: o pintor ou o compositor que se proíbe esta ou aquela combinação de cores ou conexão de acordes por serem Kitsch, o escritor que se enerva com configurações de linguagem banais ou pedantes reage tão drasticamente contra elas porque há instâncias nele mesmo que o atraem para elas. (pp. 22-23)

Na vida pulsional, a regressão não só não liberta o sujeito da pressão social a que se opunha como também acaba servindo de exemplo ao esquematismo social como a exceção que confirma a regra. Da mesma forma, a sociabilidade cotidiana que abre mão do esforço reflexivo e admite, ingenuamente, a possibilidade de manifestações da vida social, que por seus supostos descompromisso e independência, sirvam de refúgio ou contrapartida à realidade opressiva, só faz mascarar um enredamento ainda mais sufocante. A mera distração implica em descontração da tensão e contribui apenas para tornar o indivíduo ainda mais indefeso frente à dominação.

Se, de acordo com Adorno, "A própria sociabilidade é participação na injustiça", é porque ela mascara o princípio geral da socialização que isola os 
homens para melhor dominá-los. Todavia, se o isolamento é o resultado desse princípio perverso que condena até mesmo o simples e descompromissado contato com outro, como escapar desta situação?

Ao que parece, Adorno não procura um escape, mas sim a intensificação do problema. Mediante o reconhecimento da imposição desse isolamento o autor vai além e passa a ver no retraimento e na solidão um recurso contra a completa integração do indivíduo pela socialização totalitária. A insistência nesse isolamento visa a preservar uma pequena distância, que, se não pode ser considerada uma zona de segurança, garante a manutenção da tensão entre o indivíduo e a sociedade 5 .

A importância do isolamento faz com que esse tema seja uma constante em toda Minima Moralia. Ele é tratado sob vários aspectos que abrangem a questão moral, cultural, intelectual e estética. Em todos os aforismos, a necessidade de isolamento sempre é pensada como algo imprescindível, no esforço de resistência do indivíduo frente às pressões da socialização. A forma segundo a qual Adorno pensa a questão tem algumas importantes peculiaridades. Aquela que mais chama a atenção diz respeito ao fato de que, quando Adorno fala de isolamento do indivíduo como forma possível de resistência, ele se refere quase que exclusivamente ao indivíduo intelectual, quase sempre como o herdeiro da classe burguesa. Assim, nos aforismos em que o tema do isolamento adquire uma importância considerável, percebe-se que é sobre o intelectual, seus limites, contradições, responsabilidades e deveres morais que o autor reflete ${ }^{6}$.

Segundo Adorno, os intelectuais "são ao mesmo tempo os últimos inimigos dos burgueses e os últimos burgueses"(aforismo 6, p. 21). Essa formulação não indica apenas a contradição da condição de existência do intelectual, mas principalmente a contradição como condição de existência para o intelectual. E essa contradição está ligada diretamente à relação de distanciamento e envolvimento com o âmbito da reprodução material da existência.

5 Na argumentação utilizada aqui, o conceito de tensão, em si mesmo, não tem nem um aspecto positivo, nem negativo, mas aparece como consequência da oposição existente entre indivíduo e sociedade. Já a exigência de manutenção dessa tensão adquire um aspecto positivo por ser o meio de resistência à pressão social que, ao pretender aumentar aquela tensão a níveis insuportáveis, visa à sua eliminação.

6 A esse respeito, ver aforismos 1, 5, 6, 8, 31, 41, 65, 82, 86, 120, entre outros. 
Quando, em face da mera reprodução da existência, de todo ainda se concedem o luxo de pensar [os intelectuais], comportam-se como privilegiados; quando se limitam a pensar, declaram a nulidade de seu privilégio. A existência privada que anseia dar-se uma aparência de existência humanamente digna trai de imediato a esta última, na medida em que a semelhança é subtraída à realização universal, a qual, todavia, mais do que nunca tem necessidade de uma reflexão independente. Não há como sair desta situação de enredamento. (p. 21)

Assim como acontece com o isolamento da mônada, a condição de existência do intelectual traz privilégio e prejuízo indissoluvelmente ligados. Com isso, Adorno parece fazer do intelectual e seu modo de vida um representante privilegiado do isolamento da mônada. Por que o intelectual é o sujeito privilegiado? A resposta, a princípio, é simples: porque tem a possibilidade de poder manter um nível de reflexão com certo grau de independência da luta cotidiana pela autoconservação. Mas não se trata somente disso; Adorno deixa claro que o privilégio, a condição material favorável que permite o distanciamento, só existe como reflexo da restrição à sua forma de existência como indivíduo isolado. Desta maneira, o privilégio não se constitui, como tal, por si mesmo, mas somente enquanto objeto de reflexão, por parte do intelectual, daquela condição de enredamento destacada acima, ou como consciência da seguinte situação: "A sujeição da vida ao processo produtivo impõe de maneira humilhante a cada um algo do isolamento e da solidão que somos tentados a considerar como o objeto de nossa superior escolha" (p. 21).

É possível, então, entender a escolha de Adorno pela figura do intelectual como representante privilegiado da idéia de isolamento da mônada como possibilidade de resistência, pois em sua forma de vida ele traz não só o privilégio burguês, mas a possibilidade de refletir sobre a contradição desse privilégio, ao invés de simplesmente entregar-se ingênua ou anti-ingenuamente (uma oposição que para Adorno não serve a nada de bom) à sua fruição (aforismo 46, p. 63). Em outras palavras, Adorno ressalta a necessidade de que o intelectual entenda que a reflexão sobre a condição contraditória de seu privilégio é a única possibilidade justa de fruí-lo.

O privilégio do isolamento, porém, não está ligado apenas às condições materiais do intelectual. Visto que esse isolamento só se torna benéfico quando acompanhado da auto-reflexão sobre suas próprias contradições, ele também está intimamente ligado ao próprio esforço do pensar. De acordo com 
Adorno, o pensamento só é pensamento quando é capaz de penetrar a realidade e conhecer o objeto mediante a autonomia e o distanciamento que consegue manter em relação a ambos. Essa distância da realidade diz respeito, principalmente, à necessidade de autonomia do pensamento frente às influências da administração organizacional e econômica no mundo acadêmico, que faz com que as "funções intelectuais a cada minuto [tenham] que prestar contas com base no relógio de ponto".

A necessidade de que o pensamento mantenha uma certa distância da realidade mostra bem o momento privilegiado do isolamento da mônada. É somente na manutenção do distanciamento daquilo que o liga à mera reprodução material da vida e tudo o que a mantém, que o intelectual reserva-se o mínimo de autonomia para pensar a realidade de acordo com as possibilidades que fujam ao esquematismo de sua perpetuação.

Mas, porque esse distanciamento só ocorre como resultado de um privilégio e, como tal, encarna a injustiça de realizar apenas no âmbito particular aquilo que é negado no âmbito universal, à manutenção desse distanciamento está ligado também um esforço moral que exige que ele seja, o tempo todo, remetido ao seu enredamento na situação de injustiça geral. ${ }^{7}$ Ainda a respeito da dimensão moral do pensamento, Adorno ilustra bem as implicações de tal nível de exigência para o intelectual, num aforismo intitulado justamente "Para uma moralidade do pensamento" (aforismo 46):

Hoje, o que se exige de um pensador é nada menos que esteja presente, a todo instante, nas coisas e fora das coisas - o gesto do Barão de Münchhausen, que se arranca do pântano puxando-se por seu próprio rabicho, tornou-se o esquema de todo conhecimento que pretende ser mais do que constatação ou projeto. E ainda vêm os filósofos profissionais reprovar-nos de que não teríamos um ponto de partida sólido! (p. 64)

O arrancar-se pelo rabicho mostra bem a situação insólita que Adorno exige do intelectual, ou seja, que ele se encontre ao mesmo tempo dentro e

7 Sobre a forma como Adorno trabalha a questão do privilégio com o problema da justiça e da injustiça e os vincula à relação entre particular e universal, há dois aforismos bastante significativos. O primeiro é o aforismo 11, “Cama e mesa”, que mostra principalmente as consequências dessa relação quando não submetidas ao esforço reflexivo. Em outro aforismo, "Para Anatole France" (aforismo 48), Adorno esmiuça, pelo ponto de vista estético, as bases e as implicações dessa problemática. 
fora das coisas. O intelectual deve reconhecer que se encontra tão enredado pela socialização totalitária quanto qualquer um, ele deve reconhecer que está atolado. Mas deve fazer desse reconhecimento algo que vá além desse enredamento e que permita, como ponto de apoio de fora (mesmo que esteja dentro), arrancar-se desta situação - interessante notar que é na cabeça, puxando-se por seus cabelos, que o Barão encontra seu ponto de apoio surreal.

O esforço moral, entretanto, não está ligado ao isolamento (seja do intelectual, seja do pensamento) apenas pela necessidade de reflexão sobre sua condição de privilégio. A própria necessidade de manter-se minimamente afastado da realidade material e de recusar-se à participação ingênua na falsa sociabilidade é encarada por Adorno não somente como uma necessidade objetiva, mas também como um dever moral, principalmente em se tratando do intelectual. Penso ser esta a razão da extrema reserva com que o autor vê toda a participação em manifestações sociais ou culturais que não correspondam àquilo que se espera (ou que ele espera) de uma realização plenamente humana. Desde manifestações culturais mais "grandiosas" como o jazz, o cinema e a radiodifusão, até os fatos mais corriqueiros e "sem importância" do cotidiano, como a falta de janelas que se abram como asas, a existência de portas que se fecham sozinhas e até a construção sintática de um necrológio ${ }^{8}$. Tudo isso são manifestações da vida social igualmente relevantes e que exigem, como um dever moral, o trabalho de reflexão do intelectual, não apenas porque contribuem para a alienação dos indivíduos, mas porque o deter-se nelas proporciona a experiência reflexiva da vida danificada.

A visão adorniana da dimensão moral do isolamento acaba por desembocar no conceito de solidariedade, ou melhor, na necessidade de recusa da falsa solidariedade. Nos aforismos 5, já citado anteriormente, e 58, "A verdade sobre Hedda Gabler", Adorno trabalha, de forma negativa, seu conceito de solidariedade e deixa claro a importância do isolamento neste contexto.

O princípio mau, que sempre esteve escondido na afabilidade, desenvolve-se, no espírito igualitário, em direção à sua plena bestialidade. Condescendência e falta de presunção são o mesmo. Ajustando-nos à fraqueza dos oprimidos, confirmamos nesta fraqueza o pressuposto da dominação e desenvolvemos nós próprios a medida da

8 Sobre o tratamento que Adorno dá aos pequenos detalhes do dia-a-dia, ver, por exemplo, aforismos 4, 19, 102, 103, 105, 114 e 135, entre outros. 
grosseria, obtusidade e brutalidade que é necessária para o exercício da dominação. Quando, na fase mais recente, o gesto de condescendência desaparece e só o ajustamento se torna visível, é então precisamente, nesta completa ofuscação do poder, que a relação de classe disfarçada se impõe da maneira mais implacável. Para o intelectual, a solidão inviolável é a única forma em que ele ainda é capaz de dar provas de solidariedade. Toda colaboração, todo humanitarismo por trato e envolvimento é mera máscara para a aceitação tácita do que é desumano. (aforismo 5, pp.19-20)

De acordo com Adorno, solidariedade não pode estar ligada a qualquer ato de caridade ou condescendência, de forma que não existe, para o autor, a possibilidade de uma ação solidária. Isso ficou claro na análise feita até agora. Quando Adorno se refere à necessidade de isolamento, é justamente porque toda a forma de participação na vida social é participação na injustiça que dela faz parte como princípio dominante. Além disso, há o caráter totalitário daquela forma de sociabilidade, que abrange praticamente todos os espaços e envolve toda a ação humana, inserindo-a no esquematismo, por assim dizer, de retroalimentação da injustiça e da dominação.

Mas dentro de toda essa argumentação há ainda outro aspecto fundamental: para Adorno, todo envolvimento "solidário" é marcado pela noção socialmente constituída de bondade. A bondade, segundo o autor, não representa o que é bom, mas sua perversão. Isso porque ela resulta da separação do princípio moral do princípio social, sendo o primeiro desviado para a esfera da consciência privada. Com isso, o princípio moral, limitado ao indivíduo, torna sua realização, não só corrompida pela "infração do gosto e da consideração", mas também submetida ao princípio social tornado injusto, precisamente por causa daquela separação.

Ao separar o princípio moral do princípio social, deslocando-o para a esfera da consciência privada, a bondade limita-o em duplo sentido. Ela renuncia à realização da situação digna do homem, implícita no princípio moral. Em cada uma de suas ações inscreve-se uma certa resignação consoladora: ela visa à amenização, não a cura, e no fim das contas a consciência da incurabilidade pactua com esta última. Com isso a bondade torna-se limitada também em si mesma. Sua culpa consiste na familiaridade. Ela simula uma relação imediata entre as pessoas e passa por cima daquela distância, na qual somente o indivíduo é capaz de se proteger dos atentados do universal. É precisamente no contato mais íntimo que ele sente, da maneira mais dolorosa, a diferença não suprimida. Só a estranheza é o antídoto para a alienação. (aforismo 58, p. 81) 
Para Adorno, não adianta querer conciliar subjetivamente aquilo que se encontra cindido na objetividade social. O comportamento, a ação solidária, perdeu sua possibilidade de existência verdadeira quando deixou de ser verdadeira a interação dos indivíduos entre si: no isolamento da mônada, só o distanciamento é verdadeiro e somente o sentimento que é, a um só tempo, solidário e solitário é justo: "É com o sofrimento dos homens que se deve ser solidário: o menor passo no sentido de diverti-los é um passo para enrijecer o sofrimento." (aforismo 5, p. 20)

Se, como se viu até agora, não há, segundo Adorno, uma possibilidade afirmativa de individualidade, nem como um conceito originário, muito menos como experiência possível na sociedade totalitária, o conceito de resistência teria de ser remetido justamente à negatividade da forma de existência assumida pelo indivíduo. A característica de isolamento daquela existência, que levou o autor a comparar o indivíduo com uma mônada, foi o ponto de partida para a construção de um novo conceito de resistência. Se não há possibilidade de um conceito positivo de indivíduo ou de individualidade, não há como pensar a resistência em termos clássicos, ou seja, como uma forma de proteção, contra ataques externos, ou de qualquer outro tipo de influência, de uma existência afirmativa. A trama entre privilégio, dever moral e solidariedade, em que Adorno situa o conceito de isolamento, deixa clara a especificidade que o conceito de resistência assume. Este conceito, de acordo com Adorno, justapõe-se ao conceito de individualidade na medida em que o primeiro assume o segundo em toda a sua negatividade. Resistência é a forma possível de manifestação de uma individualidade, que só pode ser pensada em sua negatividade e, além disso, a possibilidade da experiência reflexiva, por parte do indivíduo, de sua própria anulação e humilhação. É a isso, a meu ver, que Adorno faz referência em um dos momentos mais desconcertantes de toda a Minima Moralia, quando escreve, já na introdução:

$\mathrm{Na}$ era da decadência do indivíduo, a experiência que este tem de si e do que lhe sucede contribui uma vez mais para um conhecimento que estava apenas encoberto por ele, na medida em que se interpretava num sentido inflexivelmente positivo como uma categoria dominante. Em face da concórdia totalitária que apregoa imediatamente como sentido a eliminação da diferença, é possível que, temporariamente, até mesmo algo da força social de libertação tenha-se retirado para a esfera individual. Nela a teoria crítica se demora e isso não somente com má consciência. (dedicatória, p. 10) 
Embora este trecho possa dar a falsa impressão de uma apologia adorniana ao indivíduo, principalmente quando lido logo na introdução, é mediante o conceito de indivíduo como mônada, isolado pela socialização totalitária e pelo modo de produção capitalista, que as palavras do autor devem ser interpretadas, e não fazendo do indivíduo um coringa astuciosamente apresentado como resposta imediata a toda a problemática social. Ou seja, é pela condição de privilégio do isolamento individual e pelas implicações de humilhação e dever moral desta condição, que se deve entender a real intenção do autor.

Com efeito, quando Adorno escreve sobre a retirada de algo da força social de libertação para a esfera individual, ele se refere à capacidade dos indivíduos em resistir. Mas, resistir a quê? Claramente àquela "concórdia totalitária". Entretanto, conforme a argumentação aqui desenvolvida, há que se notar que se a resistência é dada pela retirada da força social de libertação para a esfera individual, trata-se de uma resistência que não nasce no indivíduo, mas que a ele se remete por força, justamente, daquele movimento totalitário. O caráter desse potencial de libertação é social e a sua retirada para a esfera individual o torna praticamente inerte. Portanto, menos do que uma retirada, trata-se de um exílio no isolamento da mônada. Certamente, apesar da heteronomia do processo, tal situação implica também um momento de privilégio do indivíduo. Mas a contradição prevalece: ao mesmo tempo em que vive o privilégio de ser a célula última a guardar o potencial de libertação do todo social, vive também a humilhação de que a grandeza de tal "tarefa" só lhe foi concedida mediante a certeza social de que nenhuma libertação é possível no isolamento indigno.

A importância do conceito de resistência está ligada muito mais à decadência do indivíduo na sociedade totalitária do que à sua recuperação. A resistência do indivíduo, em Adorno, assim como sua dialética, é negativa. Sua possibilidade não está na proteção de uma individualidade falsamente existente, mas na renúncia à integração total da mônada pela falsa dinâmica entre individuação e socialização. Ou seja, a resistência se produz com o acirramento do isolamento individual, mediante a consciência moral da humilhação e da anulação intrínseca à imposição social daquele retraimento, e como experiência reflexiva do isolamento e da decadência como possibilidade privilegiada de negação da ordem totalitária. 
Com o conceito negativo de resistência, é possível tornar mais clara a exigência adorniana de criticar de forma implacável o indivíduo, mediante a denúncia de sua nulidade, sem, todavia, entregá-lo ao primado da sociedade totalitária. Percebe-se que tal concepção de resistência é o resultado depurado da exigência de Adorno de se manter a tensão do pensamento. Contudo, o conceito de resistência adorniano é negativo, não somente porque corresponde à negatividade do conceito de indivíduo a que se refere, mas também porque deixa em aberto a possibilidade (e talvez a necessidade) de sua própria negação. Em outras palavras, possibilita a abertura para o pensamento buscar uma outra realidade social em que o indivíduo, simplesmente, não precisaria mais resistir a sua dominação.

Moraes, A. L. (2005). About the Adorno's negativity concept of individual: the possible resistance. Psicologia USP, 17(3), 127-144.

Abstract: This article analyzes the concept of individual utilized by Adorno in the social critic which marked the Social Research Institute during the 40s. In order to do this, it studied many aphorisms of the Minima Moralia book. The main question is the possible relation between the annulment of individuality and the possibilities of resistance of the individual reported by the author. In this sense, concepts like individuality, monad, isolation, privilege, humiliation, moral duty, solidarity and resistance are analyzed.

Index terms: Adorno, Theodor Wiesengrund, 1903-1969. Individuality. Society.

Moraes, A. L. (2005). Sur la négativité du concept d'individu em Adorno: la possible résistance. Psicologia USP, 17(3), 127-144.

Résumé: Cet article analyse le concept d'individu utilisé par Adorno dans sa critique sociale, qui a marqué l'Institut de Recherche Sociale pendant les années 1940. Cet article analyse aussi quelques aphorismes du livre Minima Moralia. La question essentielle est la possible relation 


\section{Alexandre Lara de Moraes}

entre l'annulation de l'individualité et les possibilités de résistance du l'individu soulignées par l'auteur. J'étudie aussi les concepts suivantes : 'individualité, monade, isolement, privilège, humiliation, devoir moral, solidarité et résistance.

Mots-clés: Adorno, Theodor Wiesengrund, 1903-1969. Individualité.

Societé.

\section{Referências}

Adorno, T. W. (1993). Minima moralia. Reflexões a partir da vida danificada. São Paulo: Ática.

Horkheimer, M. (1974). Eclipse of reason. New York: Continumm.

Moraes, A. L. (2004). Indivíduo e resistência: sobre a anulação da individualidade e a possibilidade de resistência do indivíduo em Adorno e Horkheimer. Dissertação de Mestrado, Instituto de Filosofia e Ciências Humanas, Universidade Estadual de Campinas, Campinas, SP.

Recebido em: 13.10.2005

Aceito em: 9.01.2006 